\title{
DESCRIÇÃO DE OROPEZELLA PSEUDOTETRAOCELLATA SP. NOV. (DIPTERA, EMPIDIDAE, OCYDROMIINAE)
}

\author{
Rosaly Ale-Rocha ${ }^{1}$
}

\begin{abstract}
DESCRIPTION OF OROPEZELLA PSEUDOTETRAOCELLATA SP. NOV. (DIPTERA, EMPIDIDAE, OCYDROMIINAE). A new species from southeastern and southern of Brazil is described and illustrated, Oropezella pseudotetraocellata.
\end{abstract}

KEYWORDS. Diptera, Empididae, Oropezella, Taxonomy, Neotropical.

\section{INTRODUÇÃO}

O gênero Oropezella Collin tem uma larga distribuição incluindo as regiões Australiana, Neotropical e Paleártica. A espécie-tipo, O. sphenoptera (Loew, 1873) é paleártica. $\mathrm{O}$ gênero caracteriza-se pela asa estreita, célula dm com 2 nervuras, Rs longa surgindo próximo do meio da célula bm, lobo anal estreito, antenas localizadas acima do meio da cabeça, flagelo curto e arista longa. Na Região Neotropical são conhecidas sete espécies, uma chilena e seis brasileiras (Sмітн, 1962, 1967). As espécies brasileiras diferem da espécie-tipo, revisada por CHVÁLA (1983), pelo par dorsocentral pré-escutelar diferenciado, provavelmente uma característica das espécies neotropicais deste gênero. A espécie chilena difere em vários aspectos de $O$. sphenoptera, como o flagelo longo, arista ausente, célula $\mathrm{dm}$ com 3 veias e provavelmente pertence a outro gênero.

Propõe-se mais uma espécie para o gênero Oropezella procedente do Brasil.

O material é proveniente das seguintes instituições: Museu de Zoologia, Universidade de São Paulo, São Paulo (MZSP), Coleção de Entomologia Padre Jesus Santiago Moure, Curitiba (UFPR) e Instituto Nacional de Pesquisas da Amazônia, Manaus (INPA).

A terminologia adotada é a de McAlPINE (1981), exceto para a terminália masculina que segue Cumming et al. (1995).

\section{Oropezella pseudotetraocellata sp. nov.}

(Figs. 1-11)

Diagnose. Antena localizada no alto da cabeça, à frente dos ocelos; fronte obliterada pela posição da antena; 4 ocelos aparentes; face longa; tórax pruinoso, castanho, exceto a propleura, catepisterno e catepímero amarelos; acrosticais e dorsocentrais unisseriadas; abdome castanho, brilhante; pernas amarelas, exceto 3 tarsômeros distais anteriores e médios, tarso posterior e $2 / 3$ distais da tíbia posterior castanhos.

1. Instituto Nacional de Pesquisas da Amazônia (INPA), Caixa Postal 478, CEP 69011-970, Manaus, Amazonas, Brasil. (alerocha@inpa.gov.br) 


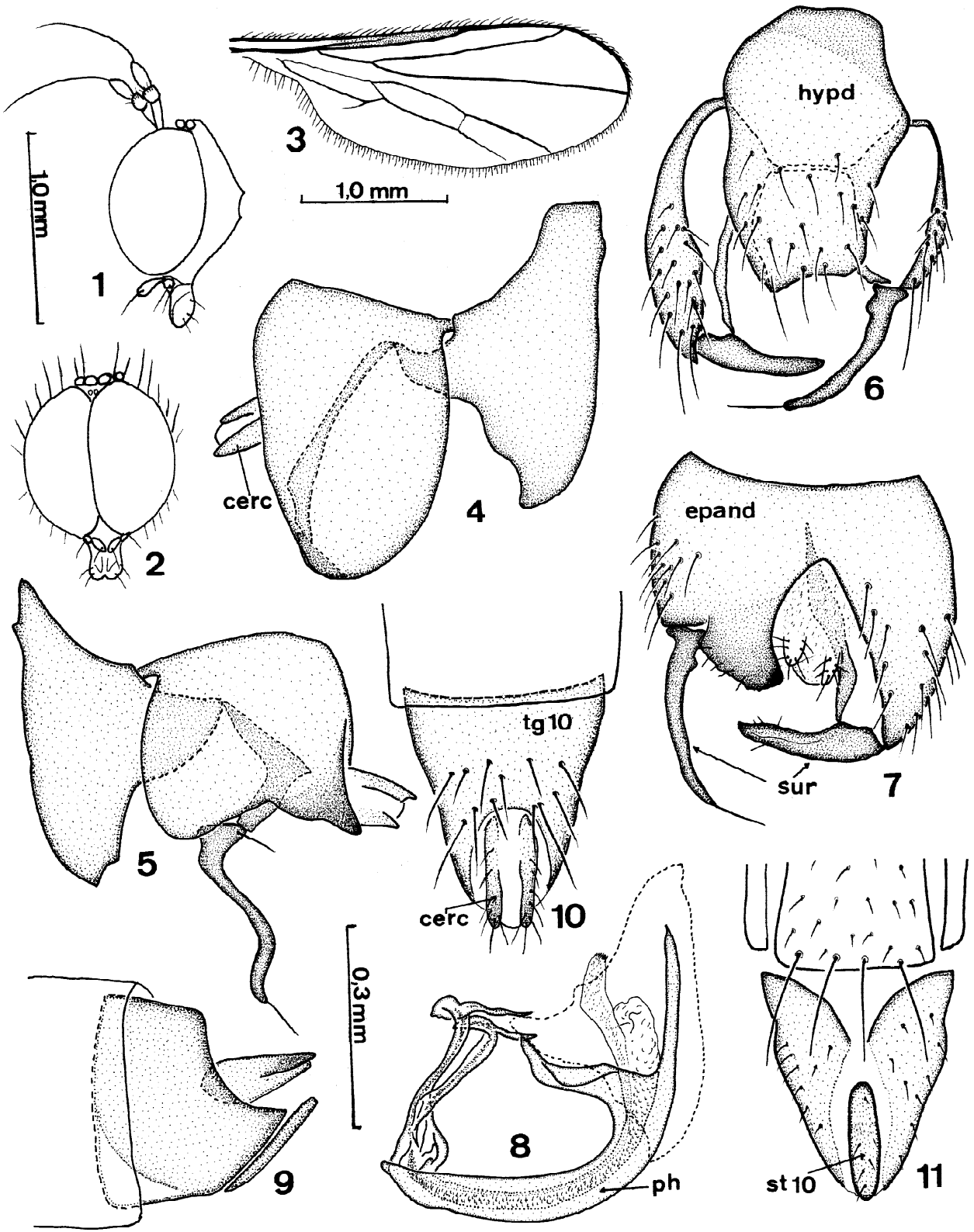

Figs.1-8. Oropezella pseudotetraocellata sp. nov., parátipo $0^{7}: 1,2$, cabeça, vista lateral esquerda e anterior; 3 , asa direita, vista dorsal; 4, 5, terminália, vista lateral direita e esquerda (falo não representado); 6, 7, terminália, vista ventral e dorsal; 8 , falo, vista lateral direita (hipândrio pontilhado); 9-11, alótipo $9: 9$, terminália, vista lateral esquerda; 10,11, terminália, vistas dorsal e ventral. Abreviaturas: cerc, cercos; epand, epândrio; hypd, hipândrio; ph, falo; st, esternito; sur, surstilos; tg, tergito. Figs. 1,2; 4 -11 na mesma escala. 
Holótipo ơ. Corpo, 2,9 mm. Asa, 2,8 mm. Cabeça (figs. 1, 2): antena castanhoclara localizada no alto da cabeça, à frente dos ocelos; escapo tão longo quanto o pedicelo e flagelo juntos; flagelo oval, pouco mais longo que o pedicelo; arista 2 vezes o comprimento da antena. Fronte reduzida, obliterada pela posição da antena. Ocelos amarelos, ocelo mediano subdividido em 2 ocelos adjacentes, aparentando, portanto, 4 ocelos dispostos sobre pequena saliência; 2 pares de cerdas ocelares, sendo o par interno longo e o externo curto. Face longa, facetas anteriores alargadas. Peças bucais castanhas; palpo curto, oval, com 1 cerda pré-apical dorsal longa e delgada; palpífer com 2 cerdas longas e delgadas; probóscide com cerdas distintas. Pós-crânio castanho, com pruína castanha; pós-oculares unisseriadas, alongadas, as superiores mais longas que as demais; cerdas ocipitais irregularmente unisseriadas, mais abundantes e curtas que as pósoculares. Tórax: castanho, exceto a propleura, catepisterno e catepímero amarelos; pruína castanha com tons de cinza; protórax com cerdas marginais curtas; escuto com cerdas curtas, esparsas, acrosticais e dorsocentrais unisseriadas. Cerdas destacadas: 1 notopleural, 1 dorsocentral pré-escutelar, 1 pós-alar, 2 pares escutelares. Abdome: castanho, brilhante; cerdas amarelas e delgadas, mais longas nas margens distais dos tergitos. Pernas: amarelas, exceto 3 tarsômeros distais anteriores e médios, tarso posterior e 2/3 distais da tíbia posterior castanhos; delgadas com cerdas amarelas. Cerdas destacadas: 1 anterior robusta próxima do ápice no fêmur médio e posterior; 1 pósterodorsal no $1 / 3$ basal, 1 anterior mediana e 1 anterior pré-apical, longas, na tíbia média; 1 ântero-dorsal mediana na tíbia posterior. Asa (fig. 3): suavemente acastanhada com nervuras castanhas e cerdas marginais amarelas; célula discal estreita. Haltere amarelo. Terminália (figs. 4-8): assimétrica, pruinosa; lamela epandrial esquerda mais curta que a direita; surstilo esquerdo longo e delgado com 1 cerda longa apical; surstilo direito mais curto e robusto que o esquerdo; falo cilíndrico, robusto, com apêndice distal bífido tão longo quanto o falo.

Fêmea similar ao macho. Ovipositor (figs. 9-11): tergito 10 projetando-se dorsolateralmente; esternito 10 pequeno; cercos pré-apicais.

Discussão. Oropezella pseudotetraocellata é facilmente distinguida das outras espécies conhecidas do gênero pelos ocelos aparentemente em número de 4 e antena localizada muito adiante do meio da cabeça, em posição quase vertical.

Material-tipo. BRASIL, São Paulo, Salesópolis (Est. Biol. Boracéia), holótipo ơ', IX. 1948, M.P. Barreto (MZSP); Rio de Janeiro, Itatiaia (Maromba), alótipo ?, VIII.1946, Barreto col. (MZSP). Parátipos: São Paulo, São Paulo (Cidade Jardim), O’ XII.1945, Barreto col. (MZSP); Paraná, Antonina (Reserva Sapitanduva),, , 29.IX.1986 (UFPR); 9 , 12.X.1986, Equipe PROFAUPAR, Malaise (UFPR); Guarapuava (Est. Águas Sta. Clara), १, 30.XI.1986, Equipe PROFAUPAR, Malaise (UFPR); Santa Catarina, Nova Teutônia (27ํ11'L), †, IX.1964, Plaumann (MZSP); 9 , XI.1964 (MZSP); $0^{7}$, XI.1971 (MZSP); $0^{7}$, XI.1972 (MZSP).

Etimologia. Grego, pseudo $=$ falso, tetra $=$ quatro, alusivo aos quatro ocelos aparentes.

Agradecimentos. Aos curadores das coleções responsáveis pelo empréstimo do material: José Albertino Rafael (INPA), Claudio José Barros de Carvalho (UFPR) e Ubirajara Martins (MZSP).

\section{REFERÊNCIAS BIBLIOGRÁFICAS}

Chvála, M. 1983. The Empidoidea (Diptera) of Fennoscandia and Denmark. II. General Part. The families Hybotidae, Atelestidae and Microphoridae. Fauna ent. scand., Copenhagen, 12:1-279. 
Cumming, J. M.; SinclaiR, B. J. \& Wood, D. M. 1995. Homology and phylogenetic implications of male genitalia in Diptera-Eremoneura. Ent. scand., Copenhagen, 26:120-151.

McAlpine, J. F. 1981. Morphology and terminology. In: McAlpine, J. F. et al. eds. Manual of Nearctic Diptera. Ottawa, Res. Branch, Agriculture Canada, v.1, p. 9-63. (Monograph nr 27).

Sмітн, K. G. V. 1962. Studies on the Brazilian Empididae (Diptera). Trans. R. ent. Soc. Lond., London, 114:195266.

. 1967. Family Empididae (Empidae, Hybotidae). In: A catalogue of Diptera of Americas South of the

United States. São Paulo, Departamento de Zoologia, Secretaria de Agricultura. v. 39, 67 p.

Recebido em 23.01.2001; aceito em 02.04.2001. 